\title{
New Orientation in the Teaching of Preventive Medicine
}

\author{
By W. PALMER DEARING, M.D.
}

\begin{abstract}
A LL OF US in this world conference on A medical education are concerned with methods of equipping the physician of tomorrow for his full role in raising the level of health of the people he serves. That role will obviously vary from place to place and from time to time, depending on the particular health problems that predominate in a given country and on the capability of medical knowledge to solve those problems.

No system of medical science and thought in the world today can claim the capacity to solve all health problems. Some diseases of worldwide prevalence, such as malaria and enteric infections, cannot be dealt with effectively without the application of engineering and sanitary science. Others, such as the nutritional deficiency diseases, cannot be dealt with effectively
\end{abstract}

without attention to economic and social conditions.

Moreover, since no physician can function apart from the society in which he lives, his role will depend upon the degree of acceptance which the people give him. H. Cullumbine (1) found, for example, in his recent survey in Ceylon, that practitioners trained in Western medicine and those trained in the Ayurvedic systems were each called upon to treat about one-fourth of the illnesses reported by some 18,000 families, and that 1 in every 20 sick persons was receiving treatment from both types. Dr. Cullumbine comments: "Patients with illnesses which Western medicine has shown it can control are placed in the care of Western practitioners; where such superiority on the part of Western medical science has still to be conclu-
Dr. Dearing has been Deputy Surgeon General of the Public Health Service since 1948 and a commissioned officer of the Service since 1934. He began his public health work as an assistant in epidemiology at the Harvard University School of Public Health working with the late Dr. Milton J. Rosenau in teaching preventive medicine and hygiene to medical students. His assignments with the Public Health Service have included studies in tuberculosis epidemiology under the late Dr. L. L. Lumsden and early work with small-film X-rays. In 1945 he was deputy chief of the Division of Public Health Methods and in 1946 was named chief of the Division of Commissioned Officers in which post he was instrumental in undertaking a complete over- hauling of policies and programs for recruitment, professional training, and assignment. During World War II he served as chief medical officer of the Office of Civilian Defense and as personnel chief of the Health Division, United Nations Relief and Rehabilitation Administration.

This paper was presented before the First World Conference on Medical Education at London, August 25, 1953. The conference, on the theme "standards of undergraduate medical education," was held under the auspices of the World Medical Association in collaboration with the World Health Organization, the Council for Organization of Medical Sciences, and the International Association of Universities. 
sively proved to the layman, then help from the traditional Ayurvedic system is sought." I venture to predict that a similar study in any other society, Western or Eastern, would reveal a comparable independence on the part of patients in their choice of physician.

Terminology differs in England and the United States, as all of us are aware. The British physician refers to "social medicine"the American, to "preventive medicine." Recognizing the terms as interchangeable, I will use the nomenclature of my own land.

\section{The Need for Orientation}

One of our philosophers, Professor Theodore M. Greene, of Yale University, describes the ideal doctor as "one who understands the human body as completely as possible in the light of all relevant sciences, who understands the human mind and its working as well as possible in the light of all relevant modern psychology and psychiatry, and who in addition understands a human being in his full potential spiritual stature" (2). In the light of modern health problems, I would add to this the requirement of an understanding of the physical and social environments in which his patients live.

If we in this conference can agree on these attributes of an ideal physician, we will readily discern the need for new orientation in the teaching of preventive medicine. For, although medical education today does a superlative job in giving the medical student a thorough grounding in anatomical and functional pathology, and skill in diagnosis and therapy, most people agree that it falls short in developing the deep understanding of human nature and human behavior which the physician must have if he is to practice prevention as well as to cure; to promote health as well as treat disease. Likewise, the medical school too often fails to prepare the student to apply the universal principles he has learned in settings other than that of the completely equipped and fully staffed teaching hospital. The medical school, therefore, needs to be as well grounded in the social milieu in which its graduates will practice as in the latest findings of medical science.

This means that no standard pattern for medical education can be applicable in all times and places. What society requires of a medical school in Edinburgh or Boston will not necessarily meet the needs of society in Thailand or Lambarene. Yet the faculties, students, and practitioners in all these widely differing societies have much to share in knowledge and experiences.

\section{Some Unsolved Problems}

In this spirit of exchanging experience, I shall talk of our efforts in the United States to reorient certain aspects of medical education from the standpoint of preventive medicine, and I shall discuss some of the unsolved problems in my country.

Like my colleagues in public health work, I know that preventive medicine is not the exclusive field of the public health specialist. The increasing problem of cardiovascular diseases and cancer, of diabetes, rheumatic conditions, and mental disorders cannot be controlled by environmental sanitation, by immunization, or by quarantine. The recent shifts in the major causes of death and disability require the practicing physician to use preventive techniques in combating the health problems of a population whose proportion of old people is increasing. He must use all available health resources in a community to achieve early case finding, prompt diagnosis and followup treatment, and rehabilitation servicesall contributing to prevention insofar as they forestall continuing disability and premature death.

Public health can be thought of as the organized application of preventive medicine, and traditionally it has been concerned with the prevention of health threats to the community as a whole. The private physician, when he is consulted by a person in an acute phase of illness, tends to be concerned primarily with restoration of the health of the individual.

Medicine has made phenomenal progress in diagnostic and therapeutic techniques, and medical education is geared to introduce the student without delay to new developments in these techniques. The medical schools have well-established departments in the basic and clinical sciences staffed by specialists who keep abreast of current advances in their fields. What is lacking is equal concern to advance 
the knowledge and application of preventive measures in controlling the conditions that undermine health.

\section{Social Changes Affecting Health}

During the last half century revolutionary changes have occurred in community life in the United States. In place of the large stable family in a small, self-contained community, where social relationships are well established and all age groups have a place, we find smaller family groups that move frequently from place to place and maintain few continuing contacts with their neighbors and relatives. Earlier dependence on grandparents and aunts and cousins in time of illness or economic distress is being replaced by dependence on the community and its institutions.

Concurrently, methods of production have vastly improved, making possible higher standards of living. Education at all levels has become more widely available. Regional differences and barriers are diminishing under the impact of rapid communications. The interdependence of the welfare of the individual and the community is manifested in the growth of a multiplicity of community hospitals, public health departments, social welfare agencies, and systems of social insurance which have developed to meet newly identified needs.

Conditions of work, increased leisure time, and diversified recreational activity also manifest sharp contrasts with the past. High tension in both work and play and problems of personal relationships produce or intensify not only the emotional but also many of the physical disorders that are prevalent today. Prevention and treatment of these disorders require knowledge of the interplay of personal and environmental forces which condition man's behavior and his health.

Moreover, there is need for a new look at the modern environment. Preventive medicine research in the past found the sources of many infectious diseases in the insanitary environment, and today it is necessary to study the industrial and urban influence as the possible source of continuing and new health hazards which may be controlled on a communitywide basis. Pollution of the air and water by industrial wastes, substandard housing, and ex- posure to new chemicals of unknown toxicity are all parts of the modern environment which contribute to the major health problems of the United States.

\section{The Physician's Role in Preventive Medicine}

The changes in American life have been accompanied by parallel changes in medical practice. Forty years ago, the family practitioner had intimate personal knowledge of his patients and their families. Today, however, he is yielding ground to relatively impersonal hospital practice by specialists, each often concerned with but a fraction of the total problem confronting the patient. At the same time, increased scientific knowledge and public understanding of health requirements have broadened the demands upon the medical profession.

Today's physician should be equipped to deal with the effects of the total environment on health-the social environment as well as the physical. He should be prepared to plan the total health care of the patient, preventive as well as therapeutic. Exclusive attention to a restricted range of biological phenomena can no longer be considered good medical practice.

There are many evidences that undergraduate medical education in the United States today falls short of preparing physicians for their full role in health maintenance and the prevention of disease. A conference on psychiatry and medical education, held in 1951, concluded that there is a concerted demand that physicians assume responsibility for the proper practice of preventive medicine. A questionnaire distributed to 3,500 community leaders throughout the United States by the conference's Preparatory Commission brought some 700 opinions that physicians of today are not giving the service expected of them. Some of the specific statements were: "They do not have time or inclination to listen to and consider the patient's feelings." "They do not have enough knowledge of emotional problems and socioeconomic family backgrounds." "In treating physical disease, they are often out of touch with the personal and social problems and pressures of the rank and file" (3). The conference report stresses the need for a greater mutual understanding between individuals and their 
personal physicians and a greater degree of collaboration in the promotion of health.

Accurate diagnosis and prescription of remedies and treatment regimens taken by themselves may be of little avail in preventing illness or its recurrence. For example, a physician writes on Mrs. X's record : "Malnutrition slight. Inadequate intake due to poverty. Treatment: codliver oil tablets. Return in 1 month." The social worker, who has been in direct touch not only with Mrs. X but also with her family, has a broader view of the situation and, I think you will agree, a more constructive approach to treatment. She has studied the family budget and knows its limitations. She is helping Mrs. $\mathrm{X}$ to find a cheaper apartment nearer her husband's work in order to stretch the earnings. The social worker is thus taking action to prevent serious malnutrition by helping the family to have more money and food.

Another illustration comes from the family adviser service in the University of Pennsylvania Medical School. Mrs. G had high blood pressure and according to the family had no other health problems except that her father-inlaw was ailing and irritable, and the children might be better off if they could play outdoors. The student health adviser's sympathetic talks with the father-in-law induced the latter to undergo regular treatment for his pernicious anemia. The health adviser also found a nearby church whose minister was delighted to have the churchyard used as a playground. Mrs. G's blood pressure, to her surprise, kept going down. The medical student who served as the family health adviser might have needed many years of experience in practice to learn for himself that high blood pressure can sometimes be alleviated by treating some other person's ailments and by getting a playground for the children (4).

I am sure that the experience of my colleagues in other parts of the world leads to the same conclusion we are arriving at in the United States: that the diversity of specialized medical and related services available in the modern community requires today's medical student to have knowledge of all community resources for preventive medicine. He must learn how to establish working relationships among a variety of specialized personnel and facilities if people are to receive the services needed to prevent and treat illness and to return patients to useful activity.

In addition to his concern with individual patients and their families, the physician should also be prepared to assume leadership in the attack which the community makes upon health problems through the organization and operation of community health services. If medical schools are to do a good job in training the physicians for this leadership role, they must give attention to the health problems of communities as such. Medical schools as well as their graduates should realize that, if physicians relegate themselves to the role of medical technician, there is real danger that leadership in organizing medical and related services which the public demands will, by default, be forced upon others.

\section{Strengthening Communication and Teamwork}

Dr. Alan Gregg, in an address at the annual meeting of the Association of American Medical Colleges in 1952 (5), made an eloquent plea for better communication among the numerous specialists in medicine and between medicine as a whole and the public at large. He draws a striking analogy between the paralysis, necrosis, and other disturbances of function which result from disruption of the communication systems within the human body-the lymphatics, the blood vessels, and the nerves-and the eventual fate of medicine if some way is not found to foster communications between the "steadily proliferating subdivisions, bailiwicks, precincts, disciplines, and specialties." I would like to elaborate Dr. Gregg's thought to identify the social sciences-sociology, anthropology, and economics-as disciplines with which medicine must specifically improve communication.

These questions of communication and teamwork are the active concern of medical educators. The Association of American Medical Colleges joined with the American Psychiatric Association in organizing and conducting two conferences on psychiatry and medical education, one of which was mentioned earlier. The Association of American Medical Colleges similarly sponsored and took an active part in a 
Joint Conference on the Teaching of Preventive Medicine. The experience gained in these three conferences has led the Association of American Medical Colleges to plan a series of teaching institutes to cover the entire structure of medical education.

Dr. George Packer Berry, dean of Harvard Medical School and past president of the association, reports that these institutes, to be held at annual intervals, will include sessions to consider the interrelationships in teaching among groups of the basic sciences, medical ecology, clinical teaching including the internship, and specialty training and the continuing education of the physician (6). As a device to focus the interest of the several medical departments on methods of integrating their work, these institutes will promote mutual understanding and community of purpose among the various specialized subdivisions of medical education and the related institutions in the community.

A national Commission on Chronic Illness, established in 1949, held a conference on the preventive aspects of chronic disease in 1951 (y). All interested professional groups were represented. In addition to medical education, health and social welfare agencies and the public were represented. That conference produced an inventory of current scientific knowledge concerning the nature and prevention of the chronic diseases. Considered also was the problem of improving care for the chronically ill, covering such fields as professional education and organization and coordination of services. Medical educators and physicians who participate in such conferences contribute sound medical guidance. At the same time they gain a deeper insight into the skills and potential contributions of other professions in dealing with common problems.

A national conference on cardiovascular disease in 1950 (8), in addition to sections on technical knowledge and research, included important committees on community services for education and prevention, on case finding and epidemiology, on facilities and services for treatment and management, and on integration of community services. Represented in these committees were medical educators, cardiologists, health officers, hospital directors, and commu- nity service agencies. The professional education committee dwelt upon the importance of including broad knowledge of the techniques and resources for prevention in the teaching programs for every profession.

In the same year a national conference on aging and its problems (9) considered a wide variety of social and economic factors involved in satisfactory health maintenance, work, recreation, religious activity, and living arrangements for the aging population. A section of that conference also stressed the need for giving professional personnel a clearer insight into the total phenomenon of aging in addition to their specialized technical instruction.

These and other conferences, groups, and seminars have contributed materially to the complex task of pulling together the viewpoints of traditional and emerging specialties in health and related fields. They have aided in identifying common interests and purposes; and they have set a base for the interchange of concepts and ideas which we know to be important to the preventive medicine component of modern medical education.

\section{Strengthening Education in Preventive Medicine}

Let us now consider some of the specific steps that some institutions are taking to meet the challenges we have been discussing. Methods of getting the student to see patients as individuals with families and jobs; of getting social science skills and viewpoints into medical schools; and of getting medical schools and their communities into more effective relationship with each other are being actively sought.

We are trying, for example, to restore some of the values formerly realized in the apprenticeship training on which medical education was once largely based. Obviously, we do not want simply to return to the past or to discard the advances of the last century. We do want, however, to improve methods by which the medical school itself can give the student an opportunity to complement his specialized training with an understanding of the role of the family physician.

Experiments being conducted in several schools in the United States represent the gradual introduction into the medical faculty 
of representatives of the social sciences. This process started with the employment of social workers to assist in the clinical teaching of the social and community aspects of medicine. More recently sociologists have been appointed to several faculties to develop the application of the social sciences to medical education and research.

As an additional step in integrating the various essential components of medical education, several schools are experimenting with the expansion of their relationships with the community. These efforts are designed to provide a useful teaching and research laboratory in comprehensive medicine and are similar to experiments being conducted in other countries for similar purposes. Dr. Richard Scott (10) has recently described the Eidinburgh University general practice teaching unit in which selected medical students are introduced to a "family doctor practice" for some 2,000 patients. The unit comprises two physicians, a public health nurse, a medical social worker, and a pharmacist. Dr. Scott points out that the stu.dents seem at first to be preoccupied with clinical matters, then become increasingly interested in the preventive aspects of general practice. During the next step the student talks more freely with the patient and becomes concerned with the physical and economic components of the patient's background.

In addition to their value as additions to the armamentarium of medical education, these developments will undoubtedly improve medical education's understanding of community needs and responses, and they will strengthen channels of communication between clinical medicine and other professional disciplines. This communication is essential to the practice of preventive medicine, and the opportunity for students to observe patients in environments other than the hospital ward should be of the greatest practical value.

Not all medical educators, however, are convinced of the feasibility or even the desirability of expanding the community relations of the medical school. A number of the deans interviewed in a study conducted by the Public Health Service (11) indicated that the costs of providing community services were a major deterrent; others cited problems of personnel shortages. Some deans even questioned the propriety of extending the influence of medical schools through community services. They feared that such developments would divert the schools' already inadequate resources from the major functions of training and research.

This fear is understandable because of the financial crisis which is facing medical education in the United States. The great advances in medical science make medical education increasingly expensive.

An understanding between the community and the medical school of the role and responsibility of each, however, would allay the fears of medical educators about the burden of community service and would help materially to solve the financial problems of many schools. The high-grade medical service which accompanies clinical teaching constitutes a great benefit to the community, but it is simply a byproduct from the point of view of the medical school. In many parts of our country, it is, nevertheless, still customary to charge the cost of this service, including the full expense of operating a university hospital, to medical education. With this sort of bookkeeping, it is not surprising that a dean should view with concern a suggestion that he add to his costs and dilute the efforts of his already overworked faculty in order to supervise medical students in the community. The community needs to appreciate the service its citizens receive, either in a hospital or elsewhere, and to work out with the medical school a proper allocation of costs and assume its responsibility of paying for the medical service. If this is done, the medical school will have adequate resources to finance what is increasingly recognized as an essential part of its educational program.

\section{Experiments in Community Service}

Despite the questions and complexities, however, some medical schools are experimenting with methods to help their students to observe and understand the influence of home and family factors on health. Some of the devices which have been developed are social case studies ; preceptorships ; assignments of students to general practice clinics or as family advisers; and participation in home care programs. 
In addition, several medical schools are assuming broader responsibilities for participating in the development of effective patterns of community health service. Each of these methods increases the student's opportunity for participation in the practice of preventive medicine and helps the medical faculty maintain a high degree of awareness of community structure and health needs.

\section{Social Case Studies}

Several medical schools in the United States are actively experimenting with methods of providing closer contact between medical students and the physical and social setting in which their patients live. One striking example is the family adviser service at the University of Pennsylvania Medical School (12). In this program a student, throughout his 4 years of undergraduate training, observes and studies all factors that affect the health of a carefully selected family-housing, food, manner of living, and family relations.

Other medical schools are endeavoring to orient students in the recognition of the importance of social factors of illness by having students conduct medical-social family studies during their supervised clinical experience. These studies are made with the aid of the social service departments of the teaching hospitals and include home visits $(13,14)$.

\section{Preceptorship}

The preceptorship is an adaptation to modern standards of practice and a modern social setup of the old apprenticeship method of training. Some medical schools assign senior students for several weeks or months to preceptorships with general practitioners. At the University of Nebraska, one of several institutions which has adopted this practice, evaluation of the program indicates that it equips the student with a perspective concerning the needs of individual patients and their families, the demands of general practice, and community resources $(15,16)$. The student has an opportunity to observe the methods used by skilled physicians in serving their patients. He sees patients in their normal home and working environment and observes the way in which physicians draw on public health, welfare, and other agencies in dealing with the health and related problems of their patients.

The preceptorship system obviously needs careful selection of practitioners who can maintain close relationships with the medical schools in furthering the goals of the plan. The practitioners must, of course, have the time, competence, and type of practice needed to give satisfactory apprenticeship training. There also must be safeguards against the danger that the students will be used for services that have little educational value and thus lose the opportunity for learning the satisfaction of serving patients as people.

\section{General Practice Clinic}

Several schools are experimenting with the use of a general practice clinic for instructing students, in place of the exclusive use of specialty clinics. One such experiment is in progress at the University of Tennessee (17) where a large percentage of graduates enter general practice. Family practitioners in the community are on the staff of the "family general practice clinic." They assume primary responsibility for the care of the patient and have available specialists as necessary. The students thus have an opportunity to work with physicians who know at first hand the problems and resources of their community. They also study social and environmental factors in health and illness with the aid of a social worker assigned to the clinic.

A similar program adapted to practice in an urban area is that at the Cornell University School of Medicine (18). In this New York City institution, senior students are assigned for $221 / 2$ weeks to a combined clinic in medicine, pediatrics, psychiatry, and preventive medicine. A full-time staff from the departments of medicine and pediatrics forms a nucleus for the organization of this teaching device. The department of preventive medicine focuses all its fourth-year teaching in the clinic. A fulltime social worker and a visiting nurse are assigned to the clinic, and part-time specialist consultants are available.

There are many other developments in the direction of expanding community relations of medical schools, but these indicate the trends. 


\section{Contribution of the Social Sciences}

Mentioned earlier were the contributions the social sciences can make in the preparation of physicians for their full role in the practice of preventive medicine. By drawing on the departments of sociology, psychology, anthropology, and economics, for example, some schools are enriching the curricula of premedical and undergraduate medical education. By bringing the social case worker onto the team of physicians, students, and nurses in the experimental programs described, some medical schools are providing valuable learning experience in social diagnosis and therapy.

There are other fields in which the social sciences can be used more extensively and to great advantage in medical schools. In the selection of applicants for admission, for example, medical schools might well draw on the techniques of educational psychology. These techniques are aimed at more precise evaluation of a candidate's personal attributes so as to distinguish those individuals who give promise of success in the study and practice of medicine.

Application of new knowledge in the psychology of learning can aid the medical school in improving its methods of teaching. Recent studies clearly indicate the need for greater use of visual aids in the teaching of "didactic" subjects. Greater understanding of the dynamics of interpersonal relations, moreover, will help in promoting interdepartmental collaboration at the faculty level, both within the medical school and with other colleges of the university.

Finally, there are large fundamental problems in preventive medicine and public health which cannot be solved without the combined efforts of medical research with social and biological research. When a major health problem of a community is being solved by treating the environment-as in enteric infectionsmany millions of individuals are protected from disease without realizing what has happened.

However, when the preventive measures require individual decision and action, we are faced with fundamental problems of individual and group behavior. This is true in gaining a family's acceptance of immunization or a mother's acceptance of healthful practices in infant and child care. The task is even more difficult in gaining the cooperation of individuals and families with the physician in his efforts to prevent chronic disease and mental illness and to maintain personal health.

Research into the "how and why" of individual and group behavior is being recognized by many leaders in preventive medicine and public health as essential to professional education and to sound planning of public health programs. Such research involves both the medical and social sciences, and the medical school can be a leader and a partner, through the initiation and support of studies in cooperation with the schools of social science.

\section{Conclusions}

The 4 years that the undergraduate student spends at medical school represent, of course, only one phase-though an extremely important one- of a life-time training in preventive medicine. His home environment, his earliest schooling, and his premedical education lay the foundations for his medical career and for his role in family practice, in a clinical specialty, in industrial medicine, in hospitals, in public health, in research, or in teaching future physicans.

Raymond Allen, the physician-president of one of our large universities (19), has expressed a thought with which I would like to close. $\mathrm{He}$ says, "Medicine with its age-old concern for the sick, the poor as well as the rich, the weak as well as the strong, has been an influence for good surpassed only by the moral precepts of religion." Medicine of the future, if it is to progress as a social as well as a biological science, must broaden its outlook and adjust its educational program accordingly.

I believe we can all agree that as Dr. Allen states, medicine is coming of age as a social science in the service of society.

\section{REFERENCES}

(1) Cullumbine, H.: The health of a tropical people: A survey in Ceylon. Lancet 264: 1245-1246 (1953).

(2) Greene, T. M.: The education of the doctor in social and moral responsibility. In Trends in medical education. New York, the Commonwealth Fund, 1949, p. 90. 
(\$) Psychiatry and medical education. Report of the 1951 Conference on Psychiatric Education. Washington, D. C., The Association, 1952, pp. 123-126.

(4) Lees, H.: They're learning that patients are people. Saturday Evening Post 244: 34, 126, 128 (Oct. 25. 1952).

(5) Gregg, A.: Communication and great medicine. J. Med. Education 28: 17-21 (Jan. 1953).

(6) Berry, G. P.: Medical education in transition. J. Med. Education 28: 17-42 (Mar. 1953).

( $\gamma$ ) National Conference on Preventive Aspects of Chronic Disease: Proceedings. Raleigh, N. C., Health Publications Institute, 1952, 311 pp.

(8) National Conference on Cardiovascular Diseases, 1st: Proceedings. New York, American Heart Association, 1950, 259 pp.

(9) Man and his years. An account of the 1st National Conference on Aging. Raleigh, N. C., Health Publications Institute, 1951, 311 pp.

(10) Scott, R.: An approach to the training of medical students in the practical aspects of preventive medicine. J. Roy. San. Inst. 73: 315321 (1953).

(11) Medical school grants and finances. Part II. Financial status and needs of medical schools. Report by the Surgeon General's Committee on Medical School Grants and Finances. Public Health Service Publication No. 54. Washing- ton, D. C., U. S. Government Printing Otfice, 1951, pp. 61-62.

(12) Hubbard, J. P.: Observation of the family in the home. J. Med. Education 28: 26-30 (July 1953).

(13) Hiscock, I. V.: Clinical public health case studies by medical students, with special reference to home visits. J. A. Am. M. Coll. 14: 79-87 (Mar. 1939).

(14) Meleney, H. E., and Mortara, F.: Medical-social family studies in medical education. J. Med. Education 27: 19-23 (Jan. 1952).

(15) Clark, Katherine G.: Preventive medicine in medical schools. Report of Colorado Springs Conference, November 1952. J. Med. Education 28: 1-123 (Part 2, Oct. 1953).

(16) The place of the preceptorship in undergraduate medical education. Panel discussion. In Proc., Annual Conference on Medical Education and Licensure of the American Medical Association. Chicago, American Medical Association, 1952 , pp. 28-32.

(17) Packer, H.: General practitioner supervision. J. Med. Education 28: 12-15 (July 1953).

(18) Barr, D. P.: The teaching of preventive medicine. J. Med. Education 28: 49-56 (Mar. 1953).

(19) Allen, R. B.: Medical education and the changing order. New York, the Commonwealth Fund, 1946, 142 pp.

\section{Increase in Social Insurance Recipients}

As of July 1953, 4.4 million people were receiving old-age and survivors insurance benefits under the Social Security Act, and 2.6 million people over 65 were receiving old-age assistance payments, according to the Social Security Administration, Department of Health, Education, and Welfare.

In 37 States, more old people received these insurance benefits in 1953 than received old-age assistance. This was true of only 22 States in 1951. The States in which old-age assistance recipients still outnumber those receiving social insurance benefits are mainly agricultural and include a number of low-income States.

The major shift during the last 2 years from assistance to insurance as a source of income for the aged is largely the result of 1950 amendments to the Social Security $A$ ct which made more of the aged eligible for insurance benefits. 